Document downloaded from:

http://hdl.handle.net/10251/39800

This paper must be cited as:

Galindo, J.; Fajardo, P.; Navarro García, R.; García-Cuevas González, LM. (2013).

Characterization of a radial turbocharger turbine in pulsating flow by means of CFD and its application to engine modeling. Applied Energy. 103:116-127.

doi:10.1016/j.apenergy.2012.09.013.

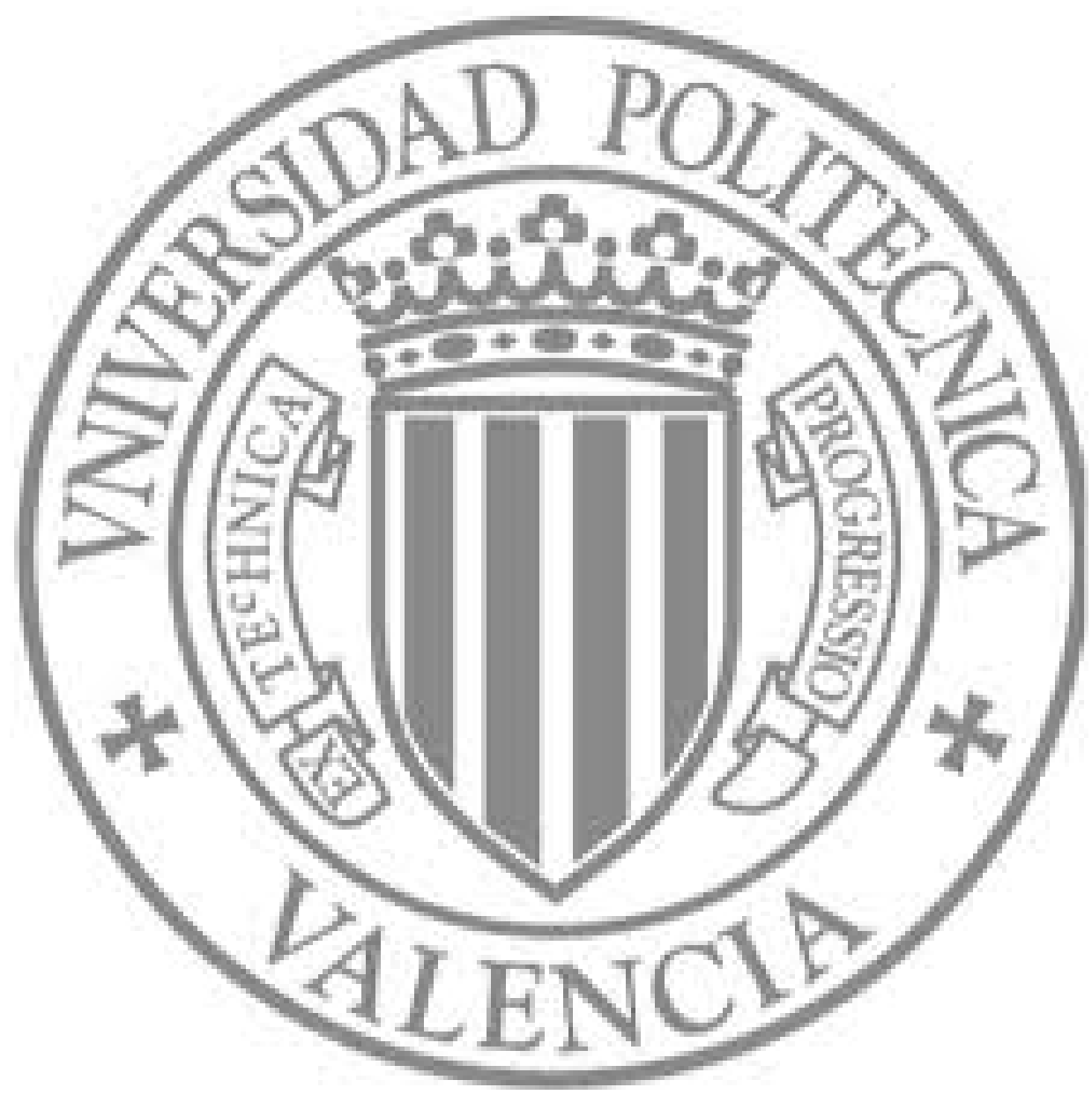

The final publication is available at

http://dx.doi.org/10.1016/j.apenergy.2012.09.013

Copyright Elsevier 


\title{
Characterization of a radial turbocharger turbine in pulsating flow by means of CFD and its application to engine modeling
}

\author{
J. Galindo, P. Fajardo(*), R. Navarro and L.M. García-Cuevas \\ CMT - Motores Térmicos, \\ Universitat Politècnica de València, \\ Camino de Vera $S / N$, 46022 Valencia
}

\begin{abstract}
This paper presents a numerical study analyzing the effect of pulsating flow in a variable geometry radial inflow turbine. The turbine behavior is analyzed under isentropic pulses, which are similar to those created by a rotating disk in a turbocharger test rig. Three different pulse frequencies (50, 90 and $130 \mathrm{~Hz}$ ) and two pulse amplitudes (100 and $180 \mathrm{kPa}$ ) were considered. Turbine flow was studied throughout the pressure pulsation cycles in a wide range of off-design operating conditions, from low pressure ratio flow detachment to high pressure ratio choked flow. An overall analysis of the phasing of instantaneous mass flow and pressure ratio was first performed and the results show the non-quasi-steady behavior of the turbine as a whole as described in the literature. However, the analysis of the flow in the different turbine components independently gives a different picture. As the turbine volute has greater length and volume than the other components, it is the main source of non-quasi-steadiness of the turbine. The stator nozzles cause fewer accumulation effects than the volute, but present a small degree of hysteretic behavior due to flow separation and reattachment cycle around the vanes. Finally, the flow in the moving rotor behaves as quasi-steady, as far as flow capacity is concerned, although the momentum transfer between exhaust gas and blades (and thus work production and thermal efficiency) is
\end{abstract}

Email address: galindo@mot.upv.es, pabfape@mot.upv.es, ronagar1@mot.upv.es, luiga12@mot.upv.es (J. Galindo, P. Fajardo ${ }^{(*)}$, R. Navarro and L.M. García-Cuevas) 
affected by a hysteretic cycle against pressure ratio, but not if blade speed ratio is considered instead. A simple model to simulate the turbine stator and rotor is proposed, based on the results obtained from the CFD computations.

Keywords: CFD Simulation, Pulsating flow, Radial turbine, Turbocharger, Turbine modeling, Quasi-steady assumption

\section{Introduction}

Axial, radial and mixed-flow turbines are used in all kinds of power-plants, ranging from the large turbines used in aircraft propulsion and steam turbines electric generators to the smaller ones used in micro gas turbines or automotive turbochargers. The importance of optimizing these energy conversion devices is clear, as has been shown by Korakianitis et al. [1], who presented a methodology for designing high efficiency turbine blades. Computational Fluid Dynamics (CFD) is a valuable tool for characterizing the performance of turbomachinery. 3D-CFD codes provide an accurate solution of the flow field of the system studied. Zhang et al. [2] performed a numerical analysis to optimize turbine blades and analyze their effect on efficiency and thereby showed the suitability of CFD for turbomachinery design.

Turbocharging is one of the most important technologies for the automotive industry. This technology is well-established for the diesel engine sector [3] and its use in gasoline engines has been steadily increasing in the past decade. The use of turbochargers enables reductions of engine cylinder volume and weight without reducing the power and torque produced. At the same time this technology reduces fuel consumption and emissions, which is vital for successfully fulfilling the current legal restrictions. The increasing use of turbochargers is leading to interesting developments in turbocharger technology. For instance, turbine vanes have evolved from being simple flat plates to the aerodynamically-shaped profiles of the latest designs. Another development was the variable geometry turbine (VGT), which improves engine transient performance [4]. The use of VGT is nowadays a common feature in the diesel engine sector. In order to keep improving turbocharger efficiency, it is necessary to understand and fully characterize its internal flow behavior. In this way, Jiao et al. [5] performed a numerical analysis of the flow field in a turbocharger compressor.

When a turbine is installed on a reciprocating engine, the inlet flow is not steady. The turbine receives a highly pulsating flow from the cylinders 
6, 7, 8. These pulses cause the turbine to operate in a wide range of working conditions, reaching extreme off-design points. In the past, most research and characterization of radial turbines was performed at constant flow conditions, using both experimental [9] and numerical [6] approaches. In order to deal with off-design steady conditions, an extrapolation methodology was presented in 10. In recent times, more attention has been paid to the analysis of pulsating flow in turbines. Baines [1] gives an overview of the different methods used for understanding pulsating flow in a turbine and the factors that influence turbine performance. Papers based on experimental work discuss accumulation and/or wave effects in the turbine and how the signals measured upstream and downstream have to be shifted in order to properly compute performance maps (flow capacity and isentropic efficiency). On the first issue there is general agreement that all the accumulation and wave effects are located in the volute, whereas the impeller can be considered as quasi-steady [12]. There is also a discussion on whether signal shift should be carried out using flow velocity or the speed of sound [13, 14]. Papers using CFD are generally focused on comparing the results against experiments and how the set-up should be defined [15, 8. One of the points of controversy is how impeller movement is to be reproduced and there are two different approaches on this issue. On one hand, the Multiple Reference Frame (MRF), also known as the frozen rotor, keeps the mesh stationary and simulates the movement by using a rotating coordinate system. The main advantage of the MRF approach is its low computational cost, at the expense of neglecting the blade passage effect and the stator-rotor interaction. On the other hand, the Sliding Mesh Model (SMM) actually moves the rotor mesh. Palfreiman et al. [16] considered that the frozen rotor approach may have some impact on the results. Similar conclusions might be found for turbocompressors in Liu et al. [17]. However, less attention has been paid to using CFD calculations to compare steady and pulsating flow operating points in order to support the conclusions of other authors. Aymanns et al. [18] recently did this for a waste-gated nozzleless turbine, showing flow capacity and efficiency plots for the turbine impeller which support its quasi-steady behavior.

In this work, CFD simulations were used to analyze the internal pulsating flow in a vaned nozzle, variable geometry turbine (VGT). In order to analyze the effects of pulsating conditions, the different turbine components, i.e. volute, nozzles and rotor, were studied separately. The paper is presented as follows. The numerical model and set-up used are first described. The results obtained using steady boundary conditions are then given. The 
pulsating flow simulations are presented, with comments on the results, and are compared to the equivalent steady-state points. In the last section, a simplified 1D-0D turbine model is proposed, able to reproduce the unsteady effects previously analyzed.

\section{Numerical Model}

The computations were performed using ANSYS-FLUENT v12. Figure 1 shows a schematic view of the turbine used in this work. The different post-processing sections considered, which are also presented in Tab. 11. can be identified in the figure. The computational domain included two zones not shown in the figure: two straight ducts which are placed at the turbine inlet (Section 1) and outlet (Section 5). The computational domain was chosen in this way in order to simulate a radial turbine operating in a turbocharger test-rig, such as the one shown in [19]. These ducts also separate the outlet boundary condition from the turbine. Little attention is paid to this feature in most of the works in the literature. However, setting the outlet boundary condition at the outlet section of the turbine, which is quite close to the impeller, makes the pressure at the impeller outlet section almost constant. In a waste-gated turbine this procedure is close to reality, due to the typical sudden increase of section at the impeller outlet in this type of turbine. Capobianco and Marelli [20] studied the pressure fluctuations at the impeller outlet of a waste-gated turbine at different opening levels. The results show that at large waste-gate openings, pressure fluctuations downstream of the impeller are not negligible. The hypothesis of constant downstream pressure commonly applied in turbocharger simulations may therefore introduce significant errors and particularly has influence in the pulsating results, as will be explained in the following analysis.

The turbine under study does not have an important expansion at the impeller outlet and therefore the validity of the constant pressure approach is not clear. In order to avoid errors when modeling the operating conditions, the outlet boundary was set farther away, thus allowing a certain pressure variation at the impeller outlet. This procedure ensures that the pressure at the turbine outlet is calculated from the flow domain and is not directly imposed.

Although a VGT was analyzed in this study, the angle was kept constant to reduce the number of parameters. In the same way the rotational speed of the turbocharger was fixed at $18953 \mathrm{rad} \cdot \mathrm{s}^{-1}$. In real pulsating operation the 
Table 1: SITUATION OF THE DIFFERENT SECTIONS CONSIDERED IN THE COMPUTATIONAL DOMAIN

\begin{tabular}{cc}
\hline Section number & Description \\
\hline 0 & Domain Inlet \\
1 & Volute Inlet \\
2 & Volute Outlet-Nozzle Inlet \\
3 & Nozzle Outlet-Rotor Inlet \\
4 & Rotor Outlet \\
5 & Turbine Outlet \\
6 & Domain Outlet \\
\hline
\end{tabular}

rotational speed would not remain constant, but it would only vary within a comparatively narrow range [13].

\subsection{Mesh Information}

The 3D mesh used for the computations is shown in Fig. 1. The main difficulty when dealing with real geometries is to achieve an appropriate mesh. The authors opted for a non-conformal mesh built from a combination of polyhedra and extruded polygons. ANSYS-FLUENT offers the possibility of generating a polyhedral mesh from a tetrahedral one, which gives better accuracy than the equivalent tetrahedral mesh [21].

A numerical accuracy study was performed to evaluate the independence of the numerical results with the mesh size. This analysis has been performed considering as characteristic cell size that used in the rotor section. The different computations for the mesh independence analysis have been done keeping a constant rotational speed $18953 \mathrm{rad} \cdot \mathrm{s}^{-1}$ and a constant mass flow rate for the different cases. The results are presented in Tab. 2.

The difference found in the last two meshes is about a $1.5 \%$ in torque and less than a $0.4 \%$ in pressure ratio. The mesh for the pulsating computations cannot be as fine as Grid 4 in the accuracy study, due to the too long computational time. The grid number 3 has been therefore used.

\subsection{Case configuration}

The solver used was the ANSYS-FLUENT v12 pressure based coupled solver. The convective terms were discretized using a second-order upwind 
Table 2: MESH INDEPENDENCE ANALYSIS

\begin{tabular}{ccccc}
\hline $\begin{array}{c}\text { Grid } \\
\text { Number }\end{array}$ & $\begin{array}{c}\text { Cells in the } \\
\text { original mesh }\end{array}$ & $\begin{array}{c}\text { Average equivalent cell } \\
\text { size in rotor }(\mathrm{mm})\end{array}$ & $\begin{array}{c}\text { Pressure } \\
\text { ratio }\end{array}$ & $\begin{array}{c}\text { Shaft torque } \\
(\mathrm{N} \cdot \mathrm{m})\end{array}$ \\
\hline 1 & 596863 & 0.5439 & 2.353 & 0.337 \\
2 & 933366 & 0.4257 & 2.297 & 0.406 \\
3 & 2039818 & 0.2585 & 2.265 & 0.442 \\
4 & 3793563 & 0.2128 & 2.273 & 0.435 \\
\hline
\end{tabular}

scheme and the unsteady terms were integrated using a first order implicit scheme in time. The time-step size should be chosen to correctly reproduce the transient behavior of the turbine, but keeping the computational cost at a reasonable level. In most of the works in the literature, a time step size ranging from $0.6^{\circ}$ [22], $1^{\circ}$ [23, 24] up to $5^{\circ}$ per time-step [25] was used. For a rotor-stator model, ANSYS-FLUENT recommends to have 20 time-steps between each blade passing [26]. Following this criterion, in this work the time step size was chosen to have 200 time steps per rotor revolution. This means a time-step size of $1.6576 \cdot 10^{-6}$ seconds. The influence of the timestep size in the numerical results has been evaluated, obtaining about a $1 \%$ difference in torque when the time step is divided by two.

Following the criteria found in the literature [27], the two-equation $\kappa-\omega$ SST turbulence model [28] was used. This turbulence model is generally preferred when dealing with turbomachinery since it behaves better than other two-equation RANS turbulence models when inverse pressure gradients and flow separation have to be considered. The boundary conditions applied were total pressure and temperature at the inlet boundary and static pressure at the outlet surface.

\section{Steady flow results}

Numerical simulations were performed for different inflow conditions. The pressure ratio through the domain was modified by setting a different total pressure value at the inlet boundary. Since the steady flow results were compared to the pulsating equivalent points, a similar pressure ratio range was considered, thus varying total pressure at the inlet section from $50 \mathrm{kPa}$ 
to $210 \mathrm{kPa}$.

The parameters typically analyzed when studying pulsating flow in turbines are the corrected mass-flow rate and efficiency as a function of the total-to-static pressure ratio. However, the definition of turbine efficiency raises certain doubts [13] due to the possible definitions of isentropic power. For this reason torque is used as a parameter in this paper instead of efficiency. Since the rotational speed of the rotor was kept constant, turbine power is proportional to torque.

Figure 2 shows the CFD results in terms of corrected mass flow for the two impeller movement techniques, as well as the results measured in a gasstand. In the figure, $\pi_{1 t 5 s}$ stands for the ratio between the total pressure at Section 1 (see Fig. 1) and the static pressure at Section 5; and $\dot{m}_{1}^{*}$ is the corrected mass-flow computed at Section 1. This notation is used in all further graphs in this paper. The figure shows a meaningful difference between MRF and SMM results. The difference is low when the turbine is working close to design conditions, but is considerable at off-design points. This difference for the corrected mass-flow is about a $5 \%$ for zones close to design conditions, but it could reach up to a $24 \%$ in off-design points. For the efficiency the difference is over 3 percentage points for the maximum efficiency and it reaches 11 percentage points for the off-design conditions. The impact of the rotor motion approach on the solution could be attributed to the stator-rotor interaction [6], which is important in the present case, since the stator is vaned and can also be enhanced by the relatively open VGT position used in this study. A similar conclusion was obtained by Liu et al. [17], who analyzed different compressors and found evidence of the importance of the mesh motion model in cases in which the interactions needed to be considered. Liu et al. also analyzed two different MRF methods and concluded that the differences found when using the frozen rotor were larger than those obtained from circumferential averaging. In the present work the MRF simulations where performed using the frozen rotor approach available in ANSYS-FLUENT. Figure 2 shows that the SMM results have a better agreement with the experimental measurements, so the SMM was therefore used in the rest of the computations performed in this paper. Hellstrom [29] gives a similar explanation for the importance of the rotor motion model in turbomachinery simulation. 


\section{Pulsating flow results}

A parametric study was carried out to quantify the influence of pulse amplitude and frequency on turbine behavior during pulsating conditions. For the sake of simplicity, the pressure pulses set at the inlet were considered to be sinusoidal. The frequencies selected for this study were 50, 90 and 130 $\mathrm{Hz}$. Considering the dominant frequency of a 4-stroke and 4-cylinder engine, these frequencies are equivalent to rotational speeds of 1500, 2700 and 3900 rpm, respectively. In any case, a general pressure signal can be decomposed into a sum of sinusoidal signals, as has been shown by Costall and MartinezBotas [30], so that it is of interest to analyze the behavior under sinusoidal signals.

Two different pulse amplitudes were considered in the present work: 50$230 \mathrm{kPa}$ and $90-190 \mathrm{kPa}$. A mean value of $140 \mathrm{kPa}$ was therefore used in all the calculations. It should be mentioned that all the pressure values given in this paper are referenced to a constant value of $101325 \mathrm{~Pa}$ and are thus gauge pressures.

Total temperature was not kept constant at the inlet boundary condition since pressure and temperature are related in compressible flows. Instead, total temperature was calculated as a function of total pressure, so that an increase in pressure leads to a rise in temperature, according to the isentropic relationship $p_{t}^{1-\gamma} T_{t}^{\gamma}=$ const. For instance, for the pulse amplitude between 50 and $230 \mathrm{kPa}$, total temperature ranges from 585 to $725 \mathrm{~K}$. This way of setting exhaust gas temperature is suitable for simulating the pulsating flow produced by a rotating disk in a gas-stand [12]. It is interesting to remark that the steady flow results used hereinafter have been computed setting the inlet total temperature making the equivalent point during the pulse. This was done to ensure that the turbine was working at the same corrected speed. The results are therefore not the same as the ones presented in Figure 2.

\subsection{Overall behavior}

The first analysis of the pulsating results was devoted to quantifying the shift in mass flow rate produced by the accumulation and wave effects. Figure 3 shows the instantaneous mass flow rate in different sections for the highest pulse amplitude (50-230 kPa) and frequencies of 50 and $130 \mathrm{~Hz}$. The pulsating simulations were set-up from a previously converged case using steady boundary conditions (but transient due to the rotor mesh movement). 
From the figure it can be seen that at least a complete period of the pulse is needed to ensure that a periodic solution is reached.

It can be said that the main source of phase-shift is clearly the volute. This seems a reasonable assumption since it is the section in which the flow spends most time, as it has a larger characteristic length than nozzles or rotor. This effect can be justified using the Strouhal Number, which by definition represents the ratio between a characteristic flow and excitation times.

$$
S t r=\frac{t_{\text {flow }}}{t_{\text {pulse }}}=\frac{\frac{L_{c}}{a+u}}{\frac{1}{f}}
$$

The characteristic length of the volute is bigger than that of the rest of the elements. It is therefore clear than the time shift is mainly produced by this element. In fact, Palfreyman et al. [15] proposed that the time-shift is proportional to the average distance traveled by the fluid in the volute. For the simulations in the present work, the mean value of the time-shift varies slightly with the frequency of the pulse, with a value around 0.0011 seconds.

The second effect that can be extracted from the plots is the influence of the plenum in the outlet section of the turbine (see Fig. 11). In the $130 \mathrm{~Hz}$ case, there is an increase in mass flow between Sections 4 and 5 , as shown in Fig. 3. The plenum therefore seems to act as a resonator at $130 \mathrm{~Hz}$.

Another fact that has to be pointed out is the pressure found at the turbine outlet. For the $130 \mathrm{~Hz}$ and amplitude of $50-230 \mathrm{kPa}$ pulse, the pressure oscillations at the turbine outlet have amplitude of $50 \mathrm{kPa}$. These fluctuations are possible due to the distance between the outlet boundary and the turbine exit which allows the pressure to evolve with the flow. On the contrary, if the outlet pressure was set close to the turbine outlet, this pressure would have been fixed, and therefore this fluctuation would have been spuriously neglected.

\subsection{Local behavior of the different components}

Flow capacity was then compared in the different turbine components. Figure 4 shows the evolution of the corrected mass flow at the volute inlet (Section 1) with the local volute pressure ratio (from Section 1 to 2). As expected, the accumulation and wave effects in the volute make the difference between steady and pulsating results increase with pulse amplitude and frequency. Figure 5 shows the same result for the nozzles zone. Due to the smaller nozzle volume and length, the accumulation and wave effects are almost negligible. Figure 6 shows the evolution of the flow capacity versus the 
local pressure ratio in the impeller. The turbine outlet region from Sections 4 to 5 is also included in this plot to take into account the mixing losses at the rotor outlet. The figure also supports the conclusion that the unsteady effects can be neglected within the impeller, due to its small characteristic length. The difference between steady and pulsating flow in the rotor is even lower than in the nozzle section. As has been mentioned above, the definition of isentropic efficiency in transient conditions introduces uncertainties related to the non-synchronized mass flow and pressure ratio [13. Here instantaneous power was considered instead. Moreover, since the rotational speed of the turbine was kept constant, the torque values (computed from the force acting on the rotor walls) and power are proportional. Fig. 7 compares the evolution of the torque obtained under pulsating conditions with the results of the steady simulations. The graphs show that the evolution of torque with pressure ratio cannot be considered as quasi-steady, in contradiction to the conclusion presented in Aymanns et al. [18. The disagreement is analyzed in further detail in the next section.

\section{Discussion of results}

This section deals with a detailed analysis of the CFD calculations. Besides the time-shift issue discussed in the previous section, there is a pulse averaging effect in the volute that can also be analyzed, due to its particular geometry. Figure 8 shows the evolution of the velocity magnitude versus the angular coordinate at the volute outlet (Section 2) at a given time. The origin of the angular coordinate corresponds to the tongue of the volute. The selected time is close to the pulse minimum of the $130 \mathrm{~Hz}$ frequency and amplitude of $50-230 \mathrm{kPa}$ case and is compared with the distribution in the corresponding steady case. From the evolution, it can be established that there is a region in the volute that is effectively behaving as in the $50 \mathrm{kPa}$ case. The rest of the volute is acting as if the pressure was higher, and is thus working under a different operating condition. It can therefore be concluded that the peaks and valleys of the time evolution of the pulsating signal are smoothed out. This effect can be appreciated in Fig. 5, in which the nozzles working under pulsating conditions do not reach the minimum mass-flow of the steady points. This effect is more noticeable as the frequency increases, since the volute outlet will be affected by a larger portion of the pulse.

Fig. 9 shows the velocity flow field in the mid-plane of the nozzles at two different points of the $130 \mathrm{~Hz}$ pulse, with the same local pressure ratio 
(approximately 1.25). Velocity contours in the two situations are similar but not identical. The velocity magnitude is higher in the upper plot. The reason is that even though the pressure ratio is the same, the total pressure at the stator inlet is not the same in the two operating conditions. In Fig. 9, the flow at the stator inlet is intrinsically non-uniform due to the shape of the volute and the effect of the screws and the vanes of the nozzle. This means the stator flow is not one-dimensional, so that not all the channels will be working under the same conditions. However this aspect is not taken into account in the current analysis, since a circumferential average was taken. During the off-design points, the flow around the stator vanes and screws detaches and reattaches; this does not necessarily happen at the same pressure ratio since it has a certain inertia. This can be seen by analyzing the two flow fields in Fig. 9, in which, even though the two cases are at the same pressure ratio, the flow is detached at some vanes in the upper case but not in the lower one. This effect makes the angle at the outlet of this section vary, thus changing the effective area of the nozzles, which can introduce part of the hysteretic cycle in the stator.

Finally, the same procedure was followed to analyze the flow-field in the rotor. The relative velocity field is shown in Fig. 10. Two points are represented with the same local expansion ratio (from Section 3 to 4), one in the rising part of the pulse and the other in the falling one. As was explained in the case of the nozzles, the absolute pressure at the impeller inlet and outlet are different in the two cases. Since the pressure ratio in the rotor is greater than in the nozzles (for this particular VGT position) the difference is more noticeable. Two conclusions can be extracted from a comparison of the images in Fig. 10. First, even though the flow at the rotor channels inlet is very different, the flow at the outlet is similar in terms of the direction of the velocity vectors and thus the effective section. This explains the slightly hysteretic behavior shown in Fig. 6, since the corrected mass-flow only depends on the effective area.

The second comment is about the very different flow pattern at the rotor inlet. Although the pressure ratio is the same, the inflow conditions are very different. Due to this effect the blade loading will be different, and thus the generated torque. The disagreement mentioned in the previous section concerning the quasi-steady behavior of torque found by Aymanns et al. [18] is the consequence of the location of the outlet boundary condition. This effect would not be appreciated if the pressure outlet boundary condition had been directly imposed close to the rotor outlet. Setting the boundary 
condition close to the turbine wheel will force the pressure to be nearly constant. Under those conditions, in pulsating flow, two operating points with equal expansion ratio will lead to similar wheel inlet conditions. Setting the boundary condition farther away from the turbine outlet, by means of a duct, allows the wheel outlet pressure to be computed from the flow field, and therefore there can be operating points with equal pressure ratio in the wheel with different inlet and outlet pressures, as the flow fields shown in Fig. 10. This situation seems to be closer to reality, since usually the turbine does not directly discharge to constant conditions. From this point of view, it is advisable to separate the outlet boundary condition from the rotor if the hysteretic effect in the torque needs to be analyzed, particularly if the turbine under study does not have a considerable expansion at the rotor outlet.

The quasi-steady assumption is not fulfilled if the evolution of rotor torque with local pressure ratio is considered. However, it can be seen that torque can correlate better with inflow conditions at the rotor inlet. In Figure[11, the torque evolution with the blade speed ratio at the rotor inlet is presented for the two $130 \mathrm{~Hz}$ pulses. The blade speed ratio $\sigma$ is computed as blade velocity divided by incident flow velocity. In this paper, the blade speed is obtained at the impeller inlet and the flow velocity is the average velocity magnitude in Section 3. It should be remembered that the blade to speed ratio is generally calculated from the isentropic velocity obtained when expanding the flow from the turbine inlet conditions to the outlet pressure, since the impeller inlet pressure is not usually measured.

\section{Application to engine modeling}

The analysis described in the preceding section gives some hints on which phenomena can be calculated with a simpler 1D or 0D model. The use of 1D engine gas dynamic models is commonplace because they allow one to predict engine performance with reasonable accuracy and limited computational cost. The use of turbocharger submodels implemented in the complete engine model is one of the key points in the development of boosting systems. Some recommendations can be given on this topic based on the analysis performed in this work, after which a turbine model covering the stator and rotor regions will be developed.

As presented in the literature [31], it is necessary to use a 1D or 0D element to reproduce the non-quasi-steady volute behavior shown in Figure 4. Most authors have successfully used a constant section 1D pipe with half of 
the volute length, which accounts for the accumulation and wave transmission effects. However, the non-uniformity of the flow in the volute outlet section during the pulse transmission plotted in Figure 8 cannot be captured with such a model. This could be done with a quasi-2D model of the volute, in which the tangential and radial components are calculated by imposing conservation of angular momentum, similar to the work presented by Bozza et al. 32] for a centrifugal compressor.

In this paper, the conclusion for the vaned stator is that there is a small hysteretic result partly produced by aerodynamic effects. This variation causes the flow angle at the outlet of the nozzle to change throughout the pulse. However, since the hysteresis is small it is considered to be negligible for the current development of the turbine model. As stated in the preceding section, it was observed that rotor flow capacity behaves in a quasi-steady manner, so that it could be computed using a zero-dimensional throat model. In the case of the generated torque, it does not behave as quasi-steady if it is presented versus the pressure ratio, since it depends on the conditions at the impeller inlet.

\subsection{Proposed model}

A new radial turbine model is here proposed, based on the results of the previous sections. The model will work with the instantaneous values of the total pressure and temperature at the stator inlet (Section 2) and the static pressure at the rotor outlet (Section 4). The model is broken up into three submodels: one simulating the stator, one for the rotor, and the intermediate deposit to decouple the response of the other two. This procedure is similar to the one used in a previous model developed by the authors' group [33]. The different thermo-fluid-dynamic processes considered in the model are shown in the h-s diagram presented in Fig. 12.

The numeration of the intersections varies due to the intermediate deposit. To clarify the subscripts notation followed in this section it should be remarked that:

- Section 3 corresponds to the stator outlet and Section 4 to the rotor outlet.

- The flow entering the plenum is at the same conditions as in section 3.

- The flow at the rotor inlet is at the conditions in the deposit (indicated with a $\mathrm{V})$. 
The different submodels are presented below.

\subsubsection{Stator nozzle}

The turbine stator will be treated in a similar way as in the previous model. Polytropic expansion will be considered for the evolution of the flow in the nozzle. In the current development, the value of the polytropic coefficient, $k$, is obtained from the steady computation at $140 \mathrm{kPa}$ (the mean value of pressure). The effective area will be computed from the geometric area of the stator section and the flow angle:

$$
A_{3_{e f f}}=2 \pi R_{3} \cdot h_{3} \cdot \cos \alpha_{3},
$$

where $\alpha_{3}$ is the angle between the flow velocity and the radial direction and, as previously mentioned, it changes during the pulse. To simplify this model, as a first approach, this angle is kept constant with the value extracted from the $140 \mathrm{kPa}$ steady simulation. The mass flow rate passing through the stator nozzle is therefore related to the pressure ratio in the nozzle as

$$
\dot{m}_{3}=A_{3_{e f f}} \frac{p_{2 t}}{R T_{2 t}}\left(\frac{p_{V}}{p_{2 t}}\right)^{\frac{1}{k}} \sqrt{2 \frac{\gamma}{\gamma-1} R T_{2 t}\left[1-\left(\frac{p_{V}}{p_{2 t}}\right)^{\frac{k-1}{k}}\right]},
$$

where $p_{V}$ is the pressure of the intermediate reservoir. Equation (3) is valid while the pressure ratio is lower than the critical one, $\left(\frac{\gamma+1}{2}\right)^{\frac{k}{k-1}}$. Once the critical pressure ratio is exceeded, the nozzle will be choked and corrected mass-flow will therefore no longer increase. It is worth mentioning that the discharge pressure, $p_{3}$, will be the pressure in the intermediate deposit $p_{V}$, and the discharge velocity can also be computed from the pressure ratio.

\subsubsection{Intermediate deposit}

As mentioned above, the aim of the deposit is to decouple the behavior of rotor and stator, and at the same time to simulate the hysteretic effects in the turbine. More precisely, it takes into account filling-and-emptying effects of the turbine, which are accomplished by the variation with time of the gas contained in the intermediate deposit. Additionally, due to the different inertia of energy and mass conservation, the plenum introduces some time shift between the pressure and temperature of the flow inside it. The volume of the deposit will be of the same order as the volume of the turbine. In order to model the deposit, it is necessary to define its behavior. The 
deposit receives the mass flow from the stator (Section 3) and supplies flow to the rotor inlet. In the current work, the conservation of the flow speed in the deposit is considered, $c_{V}=c_{3}$. This hypothesis can be assumed because in the flow between stator and rotor there is no sudden increase of area that could decelerate the flow. This hypothesis differs from the one followed in the previous model, in which the flow in the deposit was assumed to be stationary $\left(c_{V}=0\right)$.

In order to model the flow in the deposit, the accumulation effects will be considered by means of the mass conservation equation:

$$
\frac{d M_{V}}{d t}=\dot{m}_{3}-\dot{m}_{4}
$$

which are respectively: total mass of the air in the deposit, $M_{V}$; and the mass flow rate from the stator, $\dot{m}_{3}$, and to the rotor, $\dot{m}_{4}$. The energy conservation equation applied to the flow in the deposit establishes that:

$$
\frac{d}{d t}\left[M_{V}\left(c_{v} T_{V}+\frac{c_{V}^{2}}{2}\right)\right]=\dot{m}_{3}\left(c_{p} T_{3}+\frac{c_{3}^{2}}{2}\right)-\dot{m}_{4}\left(c_{p} T_{V}+\frac{c_{V}^{2}}{2}\right) .
$$

The flow entering the deposit comes from the stator (3) while the flow leaving the deposit $(V)$ will pass through the rotor. Additionally, the ideal gas equation is needed to compute the pressure inside the deposit, provided that its volume is known.

\subsubsection{Rotor section}

As previously mentioned, only a small hysteretic effect was found in the mass flow through the impeller, as shown in Fig. 6. In this case, the throat will be placed in a rotating channel and therefore has to be treated in a different way than the stator nozzle, since conservation equations have to be applied in the relative reference frame. Rothalpy is conserved in a rotating passage provided that: the flow is steady in the rotating frame, no friction from the casing has to be considered, and the wall of the turbine can be considered adiabatic [34]. This approach is different from the one followed in the previous model [33], in which the nozzle equation was directly used. Following the same criteria as in the case of the stator (Eq. (2)), the effective area of the rotor throat will be the geometric annular area multiplied by the cosine of the angle at the rotor outlet:

$$
A_{4_{\text {eff }}}=A_{4_{\text {geom }}} \cdot \cos \beta_{4}
$$


The conservation of energy in the rotating frame establishes that

$$
c_{p} T_{V}+\frac{w_{V}^{2}}{2}-\frac{u_{3}^{2}}{2}=c_{p} T_{4}+\frac{w_{4}^{2}}{2}-\frac{u_{4}^{2}}{2},
$$

where $w$ is the relative velocity and $u$ the blade speed or tangential velocity of the rotor, which can be expressed in terms of the rotational velocity. Mass flow rate through the rotor can be computed as

$$
\dot{m}_{4}=\rho_{4} w_{4} A_{4_{e f f}} .
$$

The evolution of flow in the rotor can be taken as polytropic, and $n$ is taken as its polytropic coefficient. Therefore, the mass flow rate through the rotor section can be computed as:

$$
\frac{\dot{m}_{4} \sqrt{R T_{V t r}}}{A_{4_{e f f}} p_{V t r}}=\left(\frac{p_{4}}{p_{V t r}}\right)^{\frac{1}{n}} \sqrt{\frac{2 \gamma}{\gamma-1}\left[1-\left(\frac{p_{4}}{p_{V t r}}\right)^{\frac{n-1}{n}}\right]-\frac{\left(u_{3}^{2}-u_{4}^{2}\right)}{R T_{V t r}}}
$$

where $T_{V t r}$ is the total relative temperature in the plenum, which means that the total temperature is calculated referring to the relative velocity $(w)$ instead of the absolute speed $(c)$. The rotation of the channel increases the critical pressure ratio of the rotor at which choked conditions exist, due to the last term inside the square root of Eq. (9). The difference between the squares of the tangential velocity of the rotor can be expressed in terms of the rotational speed of the turbine as:

$$
u_{3}^{2}-u_{4}^{2}=\left(\frac{\pi N}{60}\right)^{2}\left(D_{3}^{2}-D_{4}^{2}\right) .
$$

In Eq. (10), $D_{4}$ represents the diameter of the rotor outlet. Since the section is annular, an appropriate effective diameter should be defined. For the current computations, the following definition was used:

$$
D_{4}=\sqrt{\frac{D_{\max }^{2}+D_{\min }^{2}}{2}} .
$$

As previously mentioned, the angle at the stator outlet varies during the pulse, thus changing the incident angle at the rotor inlet. In order to consider the incident losses in the rotor, a simple model is used [35], which is based on neglecting the contribution of the tangential velocity to the rotor expansion. 
Since the radial component is the same for relative and absolute velocity, the following equation holds:

$$
w_{3_{\text {rad }}}=c_{3_{\text {rad }}}=c_{3} \cdot \cos \alpha_{3} .
$$

This means that while the relative total temperature at the rotor inlet (which is the one at the deposit) can be calculated as:

$$
T_{V t r}=T_{V}+\frac{w_{V}^{2}}{2 c_{p}}=T_{V}+\frac{w_{3}^{2}}{2 c_{p}}
$$

for the total relative pressure only the radial component of the relative velocity takes part, that is:

$$
p_{V t r}=p_{V}\left(\frac{T_{v t r}^{*}}{T_{V}}\right)^{\frac{\gamma}{\gamma-1}}=p_{V}\left(1+\frac{w_{3_{\text {rad }}}^{2}}{2 c_{p} T_{V}}\right)^{\frac{\gamma}{\gamma-1}} .
$$

\subsubsection{Turbine power}

The power output from the turbine can be computed as:

$$
P=\dot{m}_{4} c_{p}\left(T_{V t}-T_{4 t}\right),
$$

$T_{V t}$ being the total temperature at the deposit and $T_{4 t}$ the total temperature at the rotor outlet. The total temperature at the intermediate deposit can be computed as:

$$
T_{V t}=T_{V}+\frac{c_{V}^{2}}{2 c_{p}} .
$$

1 The total temperature at the rotor outlet is expressed as:

$$
T_{4 t}=T_{4}+\frac{c_{4}^{2}}{2 c_{p}}
$$

where $T_{4}$ can be obtained from the polytropic expression of the flow in the rotor, and $c_{4}$, the absolute flow velocity, can be obtained from the values of the relative velocity $w_{4}$, the blade velocity $u_{4}$, and the flow angle $\beta_{4}$. Therefore, there is no need to include an efficiency model. 


\subsection{Model calibration}

Up to this point, the different submodels for the stator and rotor section of the radial turbine have been presented. As inputs to the model, apart from the geometric data (areas), the polytropic coefficient in stator, $k$, and rotor, $n$, and the flow angle, $\beta$, at stator outlet and the rotor outlet are needed. The boundary conditions applied to the model are the temporal evolution of the total pressure and temperature at the stator inlet, and the static pressure at the rotor outlet.

The objective of this model is to be able to simulate the pulsating behavior of a radial turbine. It is clear that in order to obtain the exact response, the temporal evolution of polytropic coefficients and flow angles is needed. However, this approach would reduce the model's usefulness, since it could only be used when the evolutions are known. As previously commented, the values used are those of the steady simulation with a pressure of $140 \mathrm{kPa}$. For the current case, those values are $k=1.3213$ and $n=1.3221$. Another option would be to use the angle directly from the blades (both at the stator and rotor section), neglecting the fluid-dynamic effects. However, this approach presented a greater error.

The model was implemented in Python, using an explicit Euler time integration scheme for the equations describing the behavior of the deposit (Eqs. (4) and (5)). The time step size was selected to match the one used during the RANS simulations. The chosen volume of the intermediate plenum is $3.04 \cdot 10^{-5} \mathrm{~m}^{3}$, representing the real volume of the fluid domain of the stator and rotor zones.

To evaluate the behavior of the calibrated model, it has been used to reproduce the operating conditions of the simulations with steady boundary conditions. The results obtained with the model and the difference with the CFD results are presented in the following Tab. 3 .

The results of the model have been obtained with the model calibrated using the values of the $140 \mathrm{kPa}$ simulation. The results show the suitability of the model to reproduce the behavior of the stator and rotor sections of the turbine. It is worth mentioning that the biggest error is found in the low pressure region, in which the magnitude of the turbine power is smaller and therefore the difference has less effect in the overall value.

\subsection{Pulsating results}

Figure 13 shows the comparison of the flow capacity obtained from the simplified model and that obtained using the 3D-CFD code. Good agreement 
Table 3: ASSESSMENT OF THE MODEL UNDER STEADY FLOW CONDITION.

\begin{tabular}{|c|c|c|c|c|}
\hline \multirow{2}{*}{ Case } & \multicolumn{2}{|c|}{ Mass flow rate $\left(\mathrm{kg} \cdot \mathrm{s}^{-1}\right)$} & \multicolumn{2}{|c|}{ Power (W) } \\
\hline & Model result & Error \% & Model result & Error $\%$ \\
\hline $50 \mathrm{kPa}$ & 0.0367 & $8.56 \%$ & 884.16 & $2.68 \%$ \\
\hline $100 \mathrm{kPa}$ & 0.0692 & $0.049 \%$ & 6393.69 & $3.76 \%$ \\
\hline $120 \mathrm{kPa}$ & 0.0789 & $0.53 \%$ & 8221.37 & $3.46 \%$ \\
\hline $140 \mathrm{kPa}$ & 0.0877 & $0.69 \%$ & 9925.27 & $2.29 \%$ \\
\hline $160 \mathrm{kPa}$ & 0.0957 & $1.57 \%$ & 11504.28 & $1.37 \%$ \\
\hline $180 \mathrm{kPa}$ & 0.102 & $1.13 \%$ & 13466.450 & $2.15 \%$ \\
\hline $210 \mathrm{kPa}$ & 0.112 & $1.27 \%$ & 15590.25 & $0.45 \%$ \\
\hline
\end{tabular}

is found between the results, recovering the hysteretic loop, with only a few discrepancies found in the region of smaller pressure ratios. This difference is probably due to the variation of the flow angle at the stator outlet.

The power developed by the turbine can be computed by means of the simplified model as the difference between total enthalpy in the outlet and the inlet, using Eq. (15). The comparison between the results from the model and those from the three-dimensional CFD computations is shown in Fig. 14.

Good agreement is found in the power results. A small discrepancy is found in the upper curve of the loop in which power is over-predicted by the model. The difference between the energy computed in a whole pulse cycle for the model and the CFD is about $2.75 \%$. Once again, the value of the torque developed by the turbine can be easily estimated from the power computation since the rotational speed remains constant.

In view of these results, the model described in this section is able to reproduce the pulsating behavior of the stator and rotor on a radial turbine. In terms of the elements used, the proposed model is similar to the model previously developed by the authors' group [33]. However, there are some important differences, e.g. in computing the mass flow rate in the rotor section. Instead of a nozzle, the authors suggest the use of a rotating channel in which rothalpy is conserved. This results in an effective section less dependent on turbine speed and pressure ratio. The proposed formulation for the intermediate deposit is also different: in the new model the intermediate 
deposit is assumed to conserve the kinetic energy of the flow, while in the previous model the flow was considered to be stationary inside the deposit.

Information from a steady case is needed to calibrate the proposed model, i.e. the flow angle at the rotor and stator outlets and the polytropic coefficient of the evolution of the flow inside them. This means that the pulsating behavior could be recovered from information from a single CFD case with steady boundary conditions. Alternatively, the required information could be obtained from experimental data. On the other hand, the previous model needed the efficiency curve and the turbine map as input, in order to interpolate the results during the pulse. Thus, since the formulation of the new model is more physically-based, it has the advantage of not needing the complete map to describe its behavior.

Although the objective of this model is to analyze the turbine in pulsating conditions, it can also be used to extrapolate the turbine performance from a given point. The advantages of this type of model have been described by Payri et al. [10].

\section{Conclusions}

This paper describes a CFD analysis of the behavior of a radial turbine under steady and pulsating flow conditions. The main objective was to evaluate separately the non-steady effects in the volute, nozzles and impeller. The comparison with steady experimental results shows that the sliding mesh technique to simulate rotor movement is more suitable than the frozen rotor for this application, probably due to the nozzle-rotor interaction.

The analysis of the pulsating results shows that most of the time-shift in the mass flow occurs in the volute. This shift varies slightly with pulse amplitude and frequency. For the same reason the volute shows significant hysteretic behavior as pulse amplitude and frequency increase. The volute also exhibits an additional unsteady behavior, reducing the peak-to-valley amplitude due to non-uniform flow along the volute outlet section.

The flow in the nozzle section presents a limited hysteretic behavior in its pulsating flow capacity. This effect could be influenced by various aspects. In the first place, even though the characteristic length (wave action) and the accumulation effects of the stator can be neglected, when compared to those of the volute, there is a certain influence when the stator behavior is analyzed. Secondly, the averaging effect of the volute, which reduces the amplitude of the transmitted pulses, causes the pulsating flow capacity curve 
of the nozzle to shrink before reaching the equivalent steady values. Finally, the detachment and reattachment process of the flow in the nozzle vanes and screws and other aerodynamic effects have some influence on the hysteretic behavior. These aerodynamic transient phenomena change the flow angle at the stator outlet and therefore the instantaneous effective area of the nozzle.

The behavior of the impeller is even less affected by wave action and accumulation effects than the stator, due to its smaller size. In view of the two flow fields at the same pressure ratio obtained from the CFD simulations, it can be established that, even though the flow patterns in the rotor channels vary enormously, the flow in the smallest section (outlet) is quite similar regardless of the flow conditions at the channels inlet. This explains the small degree of hysteretic behavior when dealing with flow capacity in this region. However, the rotor inlet conditions have a huge impact on torque and therefore pulsating torque does not correlate with instantaneous corrected mass flow or pressure ratio, but correlates better with the impeller inflow conditions (velocity magnitude, blade speed ratio). It is interesting to remark, the importance of the location of the outlet boundary condition, which influences the pulsating flow results.

As a result of the CFD analysis, the authors propose a simplified model that would include a one-dimensional or quasi-two-dimensional element to represent the volute, a nozzle to represent the vaned stator, a small zerodimensional element to represent hysteresis in the stator, and a rotating channel in which rothalpy is conserved to represent the flow in the rotor.

A simplified model to simulate the behavior between the stator and rotor has been implemented in this paper. Although the implementations of the volute and outlet duct are not included in this simple model, they could be computed using a one-dimensional code. The performance of the stator and rotor model was evaluated for a pulsating simulation, showing good agreement with the CFD results. Due to the physically-based formulation, the proposed model only needs information from one steady point from a CFD computation.

\section{Acknowledgements}

The authors are indebted to the Spanish Ministerio de Economía y Competitividad through Project TRA 2010-16205. The proof-reading of the paper was funded by the Universitat Politècnica de València, Spain. 
627 ${ }_{628}$ during the calculations set-up. 


\section{References}

[1] T. Korakianitis, I. Hamakhan, M. Rezaienia, A. Wheeler, E. Avital, J. Williams, Design of high-efficiency turbomachinery blades for energy conversion devices with the three-dimensional prescribed surface curvature distribution blade design (circle) method, Appl. Energy 89 (2012) $215-227$.

[2] W. Zhang, Z. Zou, J. Ye, Leading-edge redesign of a turbomachinery blade and its effect on aerodynamic performance, Appl. Energy 93 (2012) 655-667.

[3] E. Arcaklioglu, I. Çelikten, A diesel engine's performance and exhaust emissions, Appl. energy 80 (1) (2005) 11-22.

[4] H. Chen, Turbine wheel design for Garrett advanced variable geometry turbines for commercial vehicle applications, in: 8th Int. Conf. Turbochargers and Turbocharging, Inst. Mech. Eng., 2006.

[5] K. Jiao, H. Sun, X. Li, H. Wu, E. Krivitzky, T. Schram, L. Larosiliere, Numerical simulation of air flow through turbocharger compressors with dual volute design, Appl. Energy 86 (11) (2009) 2494-2506.

[6] T. Kawakubo, Unsteady Rotor-Stator Interaction of a Radial-Inflow Turbine With Variable Nozzle Vanes, in: Proc. of ASME Turbo Expo 2010: Power for Land, Sea and Air, ASME, 2010.

[7] J. K. W. Lam, Q. D. H. Roberts, G. T. McDonnell, Flow modelling of a turbocharger turbine under pulsating flow, in: 7th Int. Conf. Turbochargers and Turbocharging, Inst. Mech. Eng., 2002, pp. 14-15.

[8] F. Hellstrom, L. Fuchs, Numerical Computation of the Pulsatile Flow in a Turbocharger With Realistic Inflow Conditions From an Exhaust Manifold, in: Proc. of ASME Turbo Expo 2009: Power for Land, Sea and Air, no. GT2009-5961, ASME, 2009.

[9] S. Rajoo, R. Martinez-Botas, Mixed flow turbine research: A Review, J. Turbomach. 130 (2008) 044001.

[10] F. Payri, J. R. Serrano, P. Fajardo, M. A. Reyes-Belmonte, R. GozalboBelles, A physically based methodology to extrapolate performance maps of radial turbines, Energy Conv. Manag. 55 (2012) 149-163. 
[11] N. Baines, Turbocharger turbine pulse flow performance and modelling - 25 years on, in: 9th Int. Conf. Turbochargers and Turbocharging, Inst. Mech. Eng., 2010, pp. 347-362.

[12] C. D. Copeland, R. Martinez-Botas, M. Seiler, Comparison Between Steady and Unsteady Double-Entry Turbine Performance Using the Quasi-Steady Assumption, J. of Turbomach. 133 (2011) 0310011/031001-10.

[13] S. Marelli, M. Capobianco, Steady and pulsating flow efficiency of a waste-gated turbocharger radial flow turbine for automotive application, Energy 36 (2011) 459-465.

[14] M. Capobianco, A. Gambarotta, Unsteady flow performance of turbocharger radial turbines, in: C405/017, Proceeding of the Institute of Mechanical Engineers, Fourth Int. Conf. Turbochargers and Turbocharging, Inst. Mech. Eng., 1990, pp. 123-132.

[15] D. Palfreyman, R. F. Martinez-Botas, N. Karamanis, Computational and experimental investigation of the aerodynamics of turbocharger mixed-flow turbines, in: 7th Int. Conf. Turbochargers and Turbocharging, Inst. Mech. Eng., 14-15 May London UK, 2002, pp. 45-59.

[16] D. Palfreyman, R. Martinez-Botas, The pulsating flow field in a mixed flow turbocharger turbine: An experimental and computational study, J. of Turbomach. 127 (2005) 144.

[17] Z. Liu, D. Hill, Issues surrounding multiple frames of reference models for turbo compressor applications, in: $15^{\text {th }}$ Int. Compressor Eng. Conf., Purdue University, 2000.

[18] R. Aymanns, J. Scharf, T. Uhlmann, D. Lückmann, A revision of Quasi Steady Modelling of Turbocharger Turbines in the Simulation of Pulse Charged Engines, in: 16 ${ }^{\text {th }}$ SUPERCHARGING CONF., 2011.

[19] F. Payri, J. Galindo, J. R. Serrano, M. A. Reyes-Belmonte, Experimental methodology to a comprehensive characterization of automotive turbochargers, in: EAEC2011-A17, Valencia, 2011. 
[20] M. Capobianco, S. Marelli, Waste-gate turbocharging control in automotive SI engines: effect on steady and unsteady turbine performance, in: $14^{\text {th }}$ Asia Pacific Automotive Engineering Conference, SAE, 2007.

[21] FLUENT, FLUENT 6.3 Validation Guide (September 2006).

[22] F. Hellstrom, L. Fuchs, Effects of inlet conditions on the turbine performance of a radial turbine, in: Proc. of the ASME Turbo Expo 2008: Power for Land, Sea and Air, GT2008-51088, 2008.

[23] A. T. Simpson, S. W. T. Spence, J. K. Watterson, A comparison of the flow structures and losses within vaned and vaneless stators for radial turbines, J. of Turbomach. 131 (2009) 247-254. 031010

[24] M.H. Padzillah, S. Rajoo, R.F. Martinez-Botas, Numerical Assessment of Unsteady Flow Effects on a Nozzled Turbocharger Turbine, in: Proc. of the ASME Turbo Expo 2012, GT2012-69062, 2012.

[25] T. Kreuz-Ihli, D. Filsinger, A. Schulz, S. Wittig, Numerical and experimental study of unsteady flow field and vibration in radial inflow turbines, J. of Turbomach. 122 (2000) 247-254.

[26] ANSYS Inc., Ansys Fluent 12.0 User's Guide April 2009.

[27] K. S. Lee, K. Y. Kim, A. Samad, Design optimization of low-speed axial flow fan blade with three-dimensional RANS analysis, J. Mech. Sci. and Technol. 22 (10) (2008) 1864-1869.

[28] F. R. Menter, Two-equation eddy-viscosity turbulence models for engineering applications, AIAA J. 32 (8) (1994) 1598-1605.

[29] F. Hellström, Numerical computations of the unsteady flow in turbochargers, Ph.D. thesis, Royal Institute of Technology KTH Mechanics (2010).

[30] A. Costall, R. Martinez-Botas, Fundamental characterization of turbocharger turbine unsteady flow behavior, in: Proc. of the ASME Turbo Expo, no. GT-2007-28317, 2007.

[31] F. Piscaglia, A. Onorati, S. Marelli, M. Capobianco, Unsteady Behavior in Turbocharger Turbines: Experimental Analysis and Numerical Simulation, SAE Paper 2007-24-0081. 
[32] F. Bozza, V. De Bellis, S. Marelli, M. Capobianco, 1D Simulation and experimental analysis of a turbocharger compressor for automotive engines under unsteady flow conditions, SAE Int. J. of Engines, 4 (1) (2011) 1365-1384.

[33] J. R. Serrano, F. J. Arnau, V. Dolz, A. Tiseira, C. Cervelló, A model of turbocharger radial turbines appropriate to be used in zero-and onedimensional gas dynamics codes for internal combustion engines modelling, Energy Conv. Manag. 49 (12) (2008) 3729-3745.

[34] S. L. Dixon, C. Hall, Fluid mechanics and thermodynamics of turbomachinery, Butterworth-Heinemann, 2010.

[35] H. Moustapha, M. F. Zelesky, N. C. Baines, D. Japikse, Axial and radial turbines, Concepts NREC, 2003. 


\section{List of Symbols}

$\begin{array}{lll}a & \text { speed of sound } & \mathrm{m} \cdot \mathrm{s}^{-1} \\ c_{p} & \text { specific heat at constant pressure } & \mathrm{Jkg} \mathrm{kg}^{-1} \mathrm{~K}^{-1} \\ c_{v} & \text { specific heat at constant volume } & \mathrm{Jkg} \mathrm{K}^{-1} \mathrm{~K}^{-1} \\ f & \text { frequency } & \mathrm{Hz} \\ k & \text { polytropic efficiency process in the stator } & - \\ L_{C} & \text { characteristic length } & \mathrm{m} \\ \dot{m} & \text { mass-flow rate } & \mathrm{kg} \cdot \mathrm{s}^{-1} \\ M & \text { mass } & \mathrm{kg} \\ n & \text { polytropic efficiency process in the rotor } & - \\ p & \text { pressure } & \mathrm{Pa} \\ P & \text { power } & \mathrm{W} \\ S t r & \text { Strouhal number } & - \\ t & \text { time } & \mathrm{s} \\ T & \text { temperature } & \mathrm{K} \\ u & \text { flow velocity } & \mathrm{m} \cdot \mathrm{s}^{-1} \\ \alpha & \text { absolute velocity angle } & - \\ \beta & \text { relative velocity angle } & - \\ \gamma & \text { specific heat ratio } & - \\ \pi & \text { pressure ratio } & - \\ \sigma & \text { blade speed ratio } & - \\ \tau & \text { torque } & \mathrm{N} \cdot \mathrm{m}\end{array}$


Sub- and Superscripts

* corrected variable. Ref. to $p_{0}, 101325 \mathrm{~Pa}$, and $T_{0} 288.15 \mathrm{~K}$

eff effective area

$t$ total

$r$ relative

$s \quad$ static

$V \quad$ deposit 


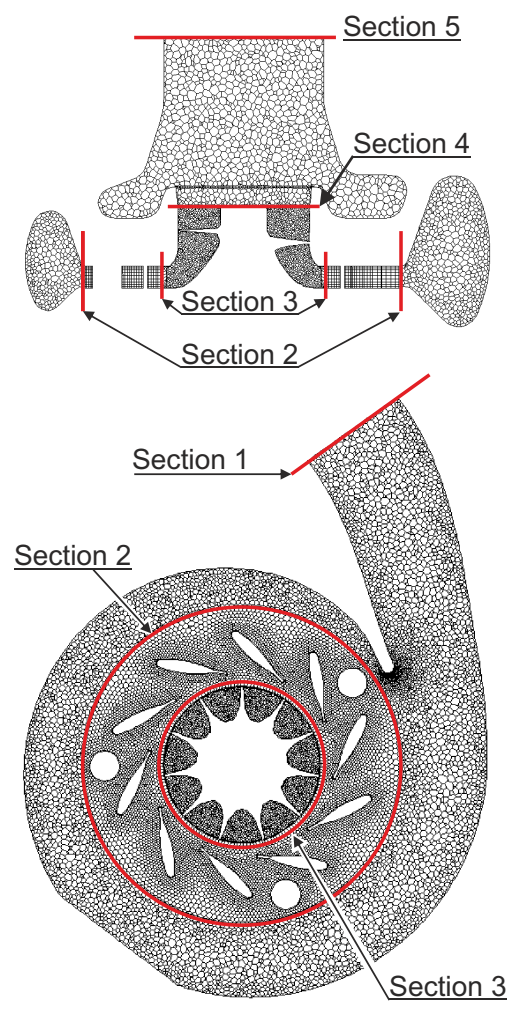

Figure 1: Schematic representation of the turbine geometry and 3D computational mesh. 

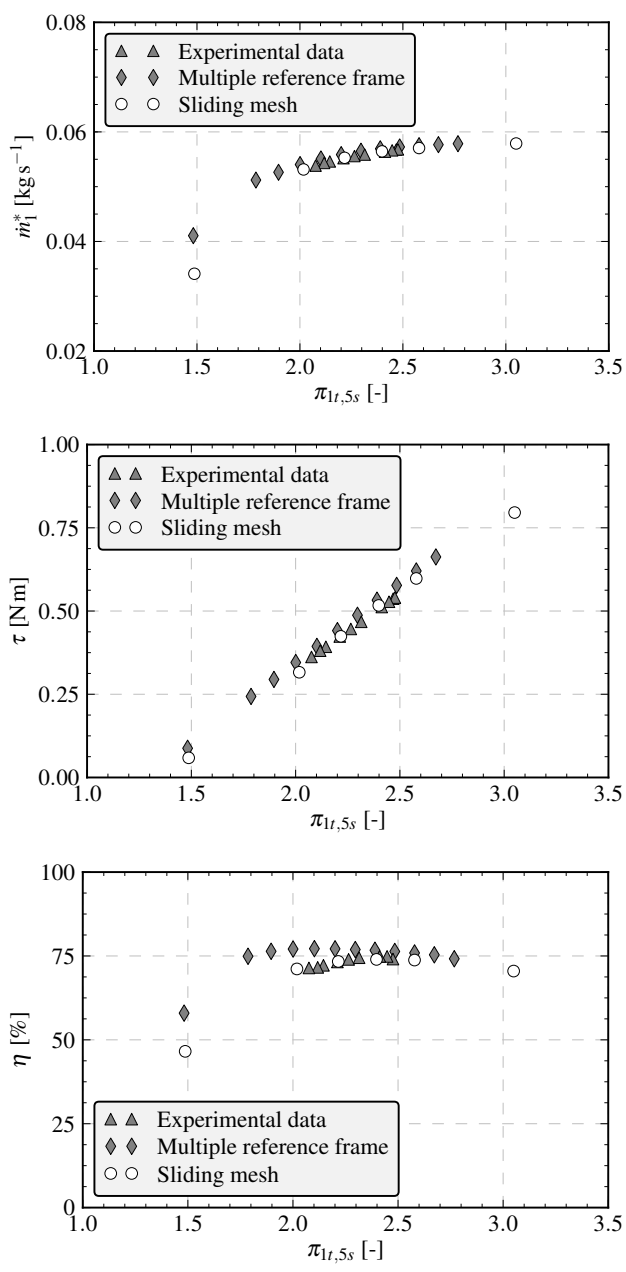

Figure 2: Characteristic curves of a radial turbine. Corrected mass flow vs overall pressure ratio (up), turbine torque vs overall pressure ratio (middle) and turbine efficiency vs overall pressure ratio. 

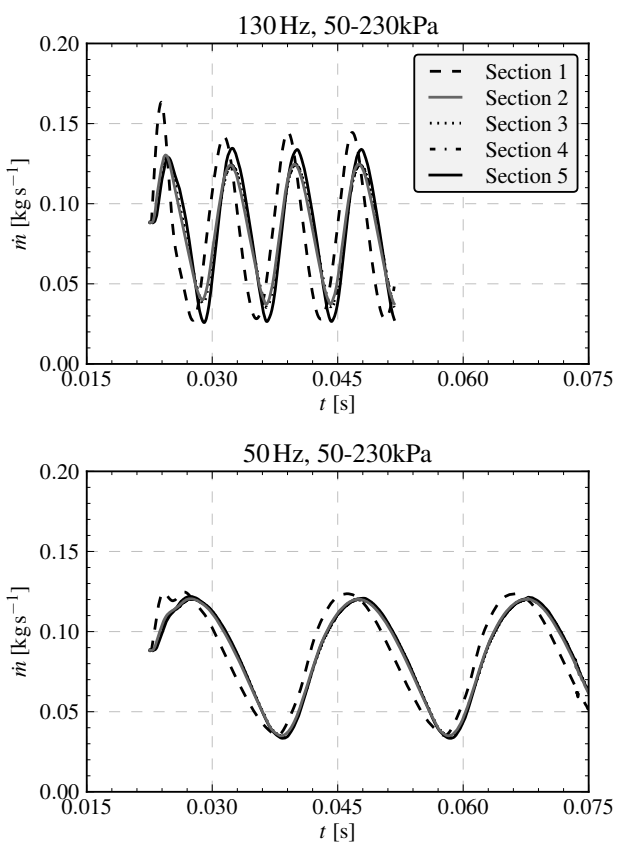

Figure 3: Temporal evolution of the mass flow rate at different turbine sections for the maximum pulse amplitude $(50-230 \mathrm{kPa})$ at two different frequencies $50 \mathrm{~Hz}$ and $130 \mathrm{~Hz}$. The time-shift introduced by the volute and the effect of the outlet plenum are indicated. 

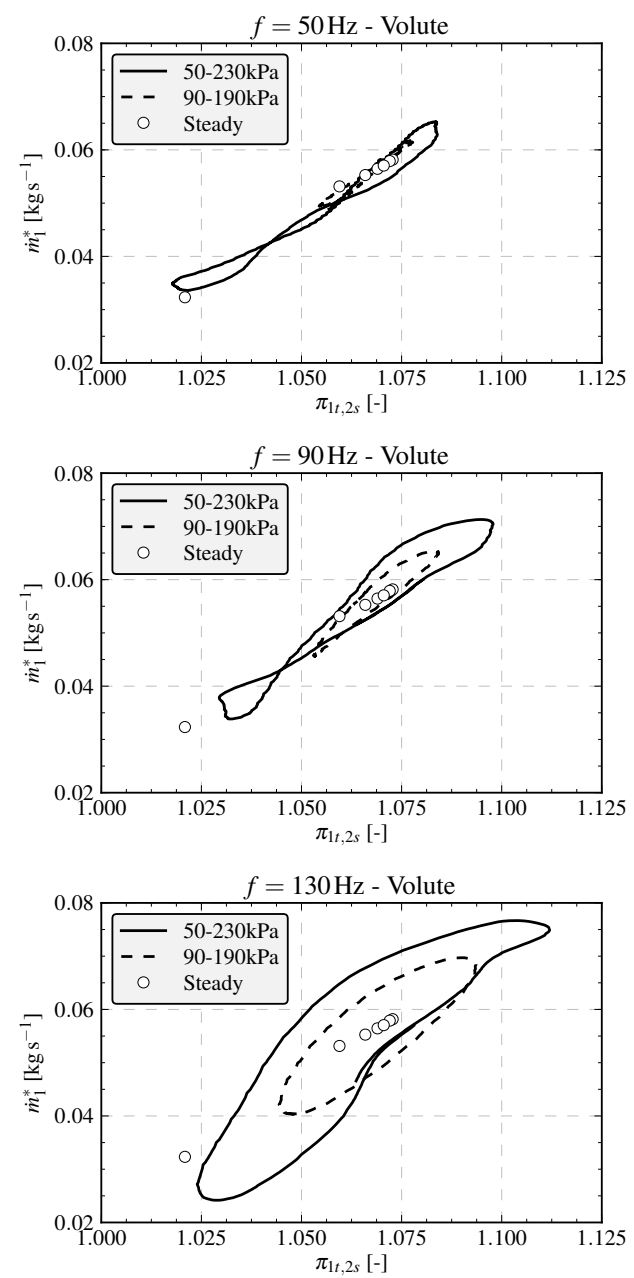

Figure 4: Corrected mass flow rate considering conditions at the inlet of the volute vs the expansion ratio in the volute. 

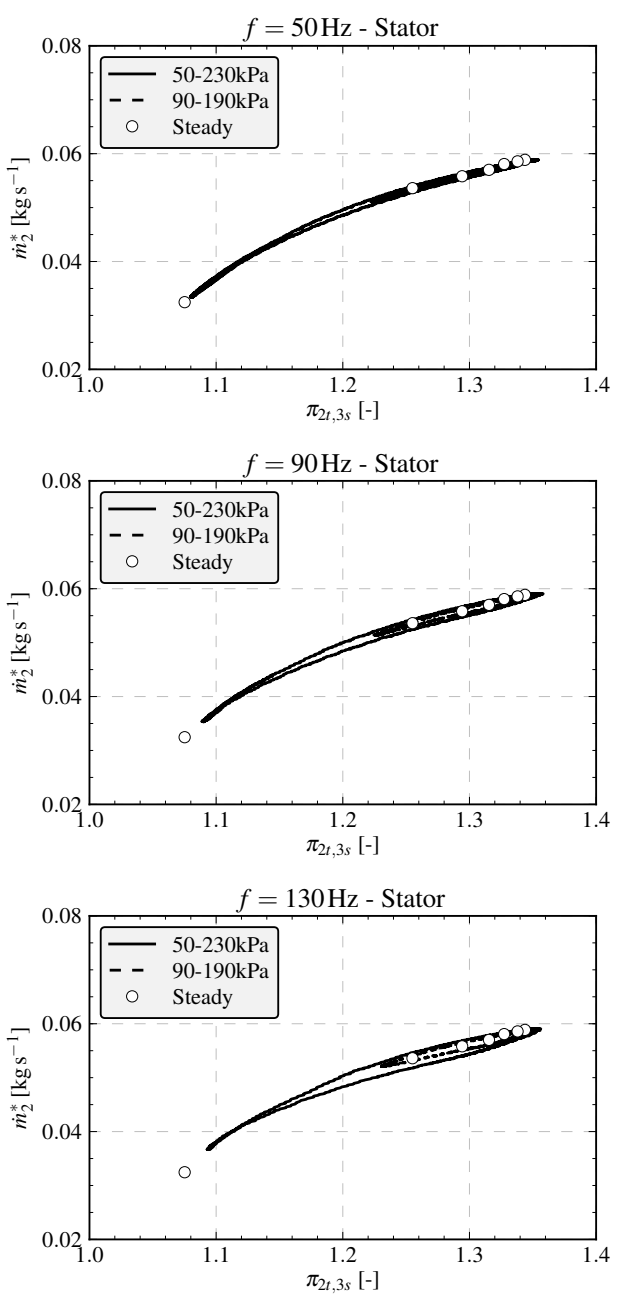

Figure 5: Corrected mass flow considering conditions at the inlet of the turbine nozzle vs the expansion ratio in the nozzle. 

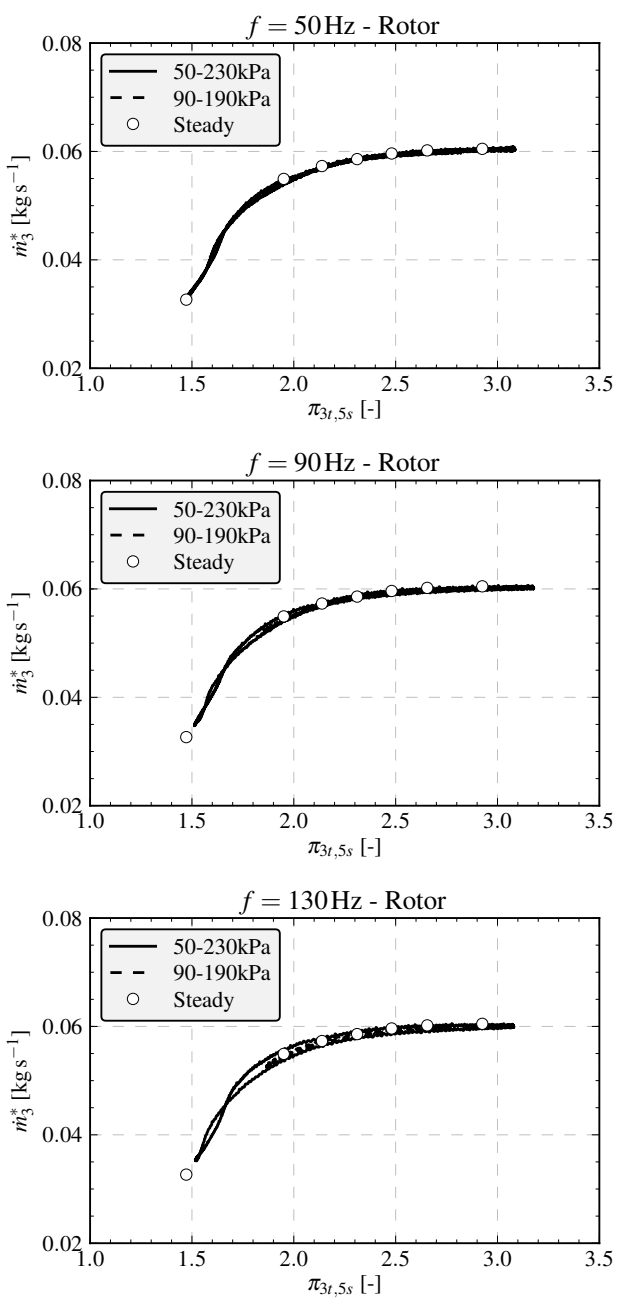

Figure 6: Corrected mass flow considering conditions at the inlet of the turbine rotor vs the expansion ratio in the rotor and outlet section of the turbine. 

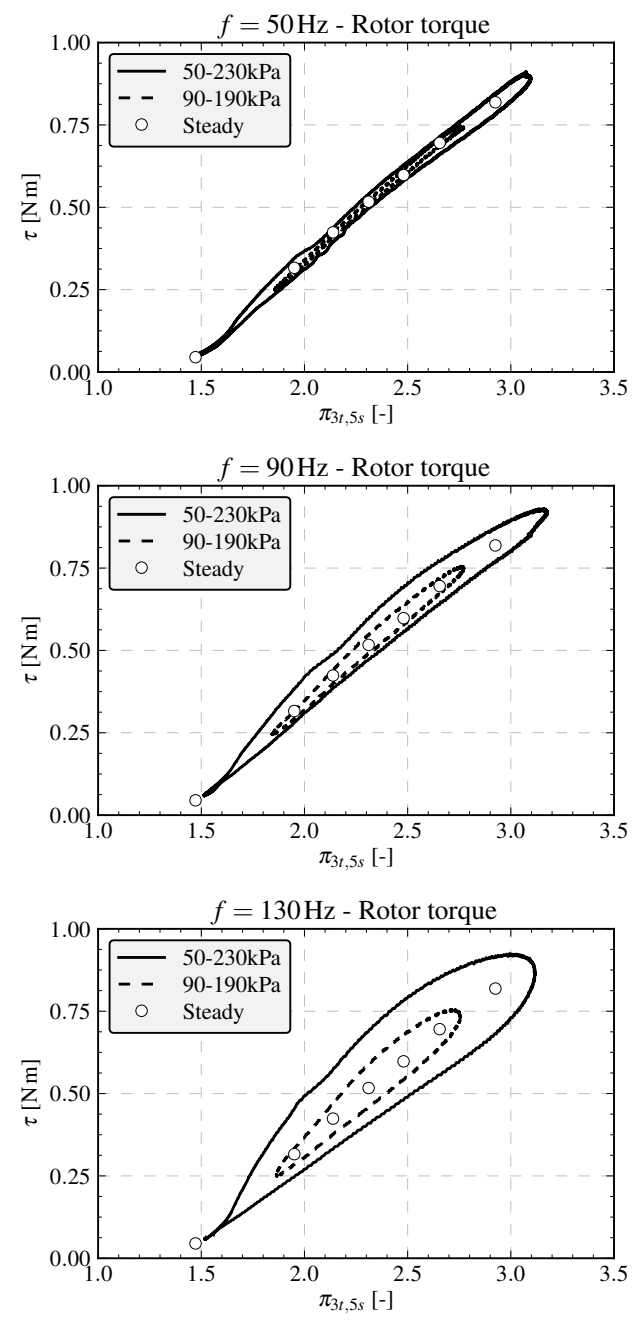

Figure 7: Turbine torque vs pressure ratio in the rotor. 


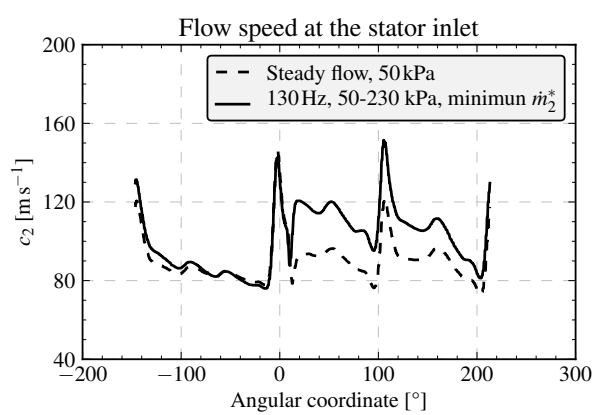

Figure 8: Evolution of the velocity magnitude with the angular coordinate at the volute outlet. 


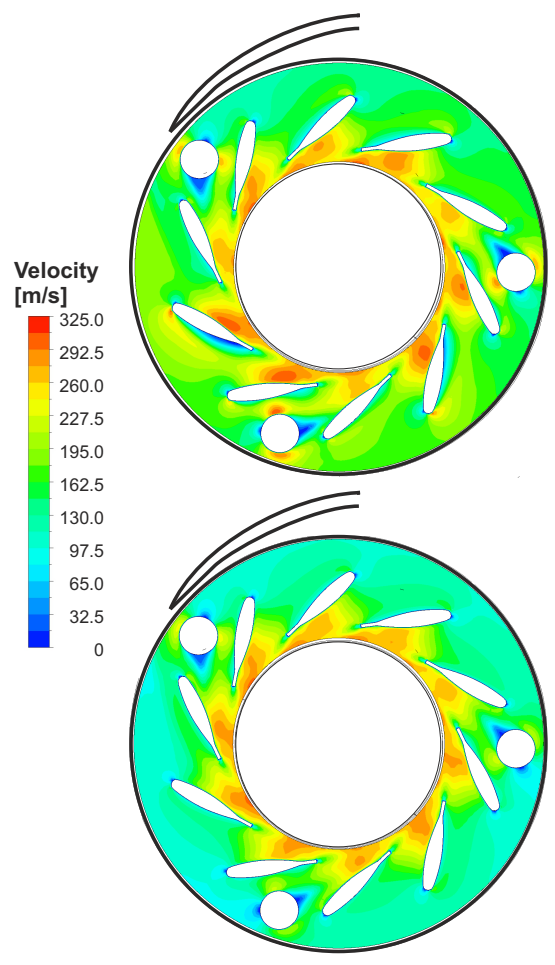

Figure 9: Velocity flow fields in the stator for two points of the pulse $(130 \mathrm{~Hz}, 50-230$ $\mathrm{kPa})$ with the same pressure ratio $\left(\pi_{2 t 3 s} \simeq 1.25\right)$. In the upper one the pressure ratio is decreasing and it is increasing in the lower one. 

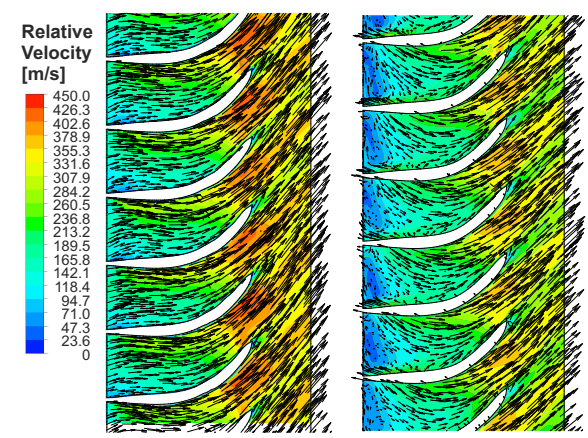

Figure 10: Relative velocity flow fields in the rotor for two points of the pulse $(130 \mathrm{hz}$, $50-230 \mathrm{kpa})$ with the same pressure ratio $\left(\pi_{3 t 4 \mathrm{~s}} \simeq 2.42\right)$. In the left image the pressure ratio is increasing, in the right image it is decreasing. 


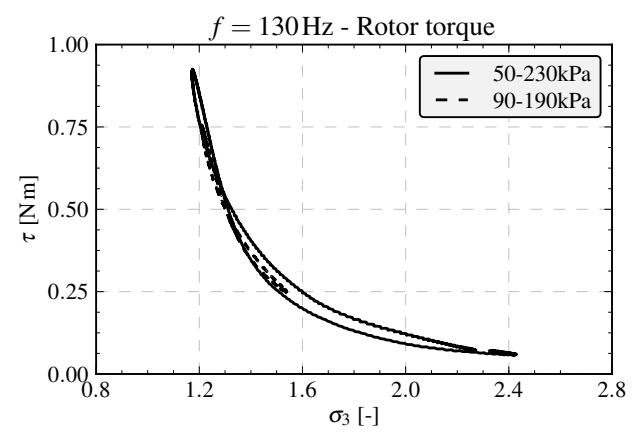

Figure 11: Turbine torque vs blade speed ratio at the rotor inlet. 


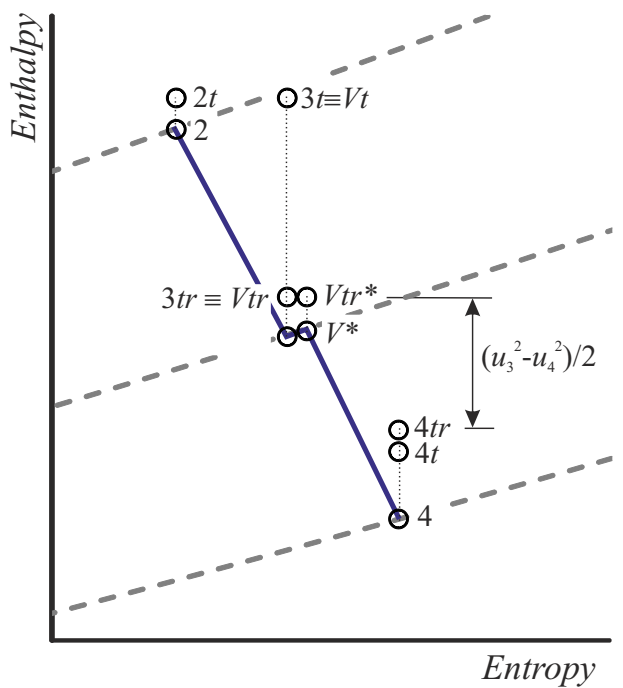

Figure 12: Enthalpy-entropy diagram of the thermo-fluid-dynamic processes considered in the model. The notation used in the diagram is described throughout section 6 . 


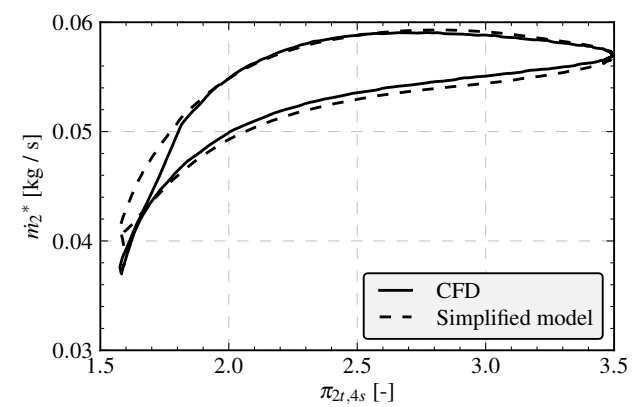

Figure 13: Comparison of the turbine flow capacity taking into account the stator and rotor sections by means of CFD and the proposed model. These results are obtained for a $130 \mathrm{~Hz}$ pulse with the highest amplitude considered (50-230 $\mathrm{kPa})$. 


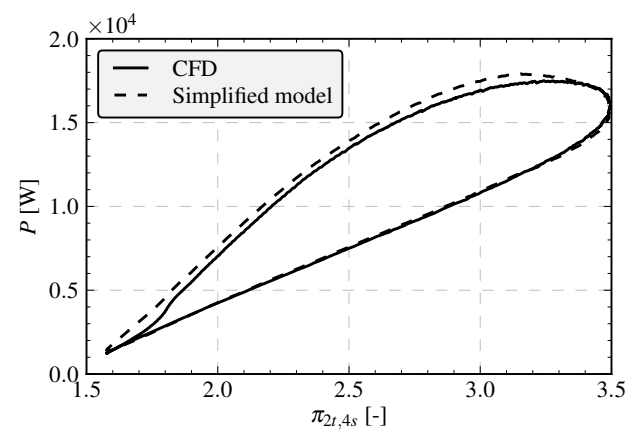

Figure 14: Comparison of power as computed by the model and that obtained from the CFD computations. These results are obtained for a $130 \mathrm{~Hz}$ pulse with the highest amplitude considered (50-230 kPa). 